\title{
Descolonizando territórios na América Latina: esforços ontológicos e epistemológicos dos povos indígenas
}

\author{
La descolonización de territorios en América Latina: Esfuerzos \\ ontológicos y epistemológicos de los pueblos indígenas \\ Decolonizing territories in Latin America: Ontological and \\ epistemological efforts of indigenous peoples
}

Marcos Mondardo ${ }^{1}$

\begin{abstract}
Resumo
O debate sobre a descolonização de territórios na América Latina/Abya Yala/Quilombola diz respeito aos esforços ontológicos (das lutas) e epistemológicos (teóricos) dos povos originários/indígenas, comunidades quilombolas, populações tradicionais e grupos subalternizados em busca de reconhecimento de seus direitos como a terra, o território, a saúde e a educação. Este texto problematiza, assim, a geografia dos povos e comunidades tradicionais da América Latina por meio da descolonização do poder e do saber. Para isso o procedimento metodológico adotado foi a pesquisa bibliográfica. A América Latina é uma construção histórica e apresenta uma ideia de um lugar do mundo como um produto colonial. Estamos imersos na "colonialidade do poder e do saber". É fundamental adotar a perspectiva decolonial na análise cultural latino-americana para imaginar horizontes emancipatórios e construir práticas de luta e resistência. As distintas realidades latinoamericanas são construídas por histórias vividas e quanto maior e mais diversos forem os números de narrativas, melhor poderemos apreender e potencializar a diversidade desse espaço, seus conflitos e lutas.
\end{abstract}

Palavras-Chave: América Latina; colonialidade; descolonização; poder; territórios.

\section{Resumen}

El debate sobre la descolonización de territorios en América Latina/Abya Yala/Quilombola se refiere a los esfuerzos ontológicos (de lucha) y epistemológicos (teóricos) de los pueblos nativos/indígenas, las comunidades quilombolas, las poblaciones tradicionales y los grupos subalternos en busca del reconocimiento de sus derechos como la tierra, el territorio, la salud y la educación. Así pues, este texto problematiza la geografía de los pueblos y comunidades tradicionales de América Latina mediante la descolonización del poder y el conocimiento. Para ello, el procedimiento metodológico adoptado fue la investigación bibliográfica. América Latina es una construcción histórica y presenta una idea de un lugar en el mundo como un producto colonial. Estamos inmersos en la "colonialidad del poder y el conocimiento". Es fundamental adoptar la perspectiva descolonial en el análisis cultural latinoamericano para imaginar horizontes emancipadores y construir prácticas de lucha y resistencia. Las diferentes realidades latinoamericanas se construyen a partir de historias vividas y cuanto mayor y más diverso sea el número de relatos, mejor podremos aprehender y potenciar la diversidad de este espacio, sus conflictos y luchas.

Palabras claves: América Latina; colonialidad; descolonización; poder; territorios.

\begin{abstract}
The debate on the decolonization of territories in Latin America/Abya Yala/Quilombola concerns the ontological (fighting) and epistemological (theoretical) efforts of native/indigenous peoples, quilombola communities, traditional populations and subalternized groups in search of recognition of their rights such as land, territory, health and education. This text thus problematizes the geography of traditional peoples and communities in Latin
\end{abstract}

\footnotetext{
${ }^{1}$ Doutor em Geografia pela UFF. UFGD/Faculdade de Ciências Humanas. E-mail: marcosmondardo@yahoo.com.br.
} 
America through the decolonization of power and knowledge. For this, the methodological procedure adopted was the bibliographical research. Latin America is a historical construction and presents an idea of a place in the world as a colonial product. We are immersed in the "coloniality of power and knowledge". It is fundamental to adopt the decolonial perspective in Latin American cultural analysis to imagine emancipatory horizons and build practices of struggle and resistance. The different Latin American realities are constructed by lived histories and the greater and more diverse the numbers of narratives, the better we will be able to apprehend and potentialize the diversity of this space, its conflicts and struggles.

Keywords: Latin America; coloniality; decolonization; power; territories.

\section{Introdução}

Isso de querer ser exatamente aquilo que a gente é ainda vai nos levar além. Paulo Leminski (1987)

Na América Latina/Abya Yala/Quilombola as lutas por corpos, terras e territórios encontram-se no centro dos discursos e das práticas dos movimentos indígenas. Nosso objetivo consiste, assim, em analisar essas lutas por meio da descolonização do poder e do saber. Este texto situa-se no contexto latino-americano do giro decolonial e ecoterritorial das lutas (SVAMPA, 2019), com ênfase para a dimensão espacial da colonialidade. Diante dos conflitos socioambientais que envolvem o ataque aos territórios dos povos indígenas e comunidades tradicionais, o espaço geográfico deve ser visto por meio de práticas verdadeiramente descolonizadoras, de luta e de resistência. O procedimento metodológico adotado foi à pesquisa bibliográfica dos estudos decoloniais. Para isso assumimos uma postura crítica frente à falta de rigor e aprofundamento dos conceitos da Geografia e da Cartografia. Esses conceitos são usados como metáforas espaciais para discutir aspectos filosóficos e literários, deixando, de certo modo, o espaço geográfico relegado a uma dimensão menor nas análises.

A América Latina/Abya Yala/Quilombola, um "continente assaltado" (GALEANO, 1987), é uma construção histórica e apresenta uma ideia de um lugar do mundo como um produto colonial. Estamos imersos na "colonialidade do poder e do saber" (QUIJANO, 2005). As nações, os povos, o comum, foram cercados e capturados pelo mercado e as corporações mandam no mundo da globalização neoliberal (DARDOT E LAVAL, 2014). É necessário, por isso, invocar a dimensão dos povos indígenas da América Latina e sua relação com a violação dos direitos humanos, à crise ambiental, econômica, geopolítica, social, institucional e civilizacional. Essa descolonização passa pela construção de "subjetividades territoriais" (KRENAK, 2019) que fazem parte dos movimentos de luta e resistência por corpo, terra e território. 
Diante da ascensão da extrema direita na América Latina/Abya Yala/Quilombola, a questão social dos povos originários e a questão de acesso aos seus territórios, tornou-se uma pauta emblemática de descolonização da política contemporânea. A descolonização, já afirmava Frantz Fanon, no clássico Os condenados da terra, em meados do século passado, é um movimento pelo qual se busca trazer à tona a reivindicação do colonizado. Nesse encontro de forças antagônicas em que ocorre a negação sistemática do Outro, "o colonialismo obriga o povo dominado a perguntar-se constantemente: 'Quem sou eu, na verdade?'” (FANON, 2005, p. 288). A violência colonial "desumaniza os homens condenados da terra", pois está relacionada ao ser, à transformação dos homens, à "criação de novos homens". O corpo, a língua e a alteridade são, como "experiências subjetivas”, necessários na própria construção do futuro político dos colonizados em suas práticas e pensamentos de "desalienação".

Os estudos decoloniais nos provocam a ver o mundo com nossos próprios olhos e estimulam a descolonizar nosso imaginário geográfico colonial e reimaginar o mundo - ou outros mundos - conforme nossa posição geográfica, condição social, de classe, de gênero, de etnia, de escolhas - o que nos ajuda a descolonizar (do ponto de vista da lógica hegemônica eurocêntrica e colonial) o nosso território. Por isso, em nossa pesquisa os territórios e territorialidades se manifestam na sua multiplicidade, mas sempre marcados pelo contexto brasileiro-latino-americano de onde os grupos e/ou sujeitos pensam, produzem e vivenciam suas experiências espaciais.

É imprescindível dialogarmos com autorxs que propõem repensar nossa forma de ver o mundo, o território, por meio da contextualização latino-americana, pelo diálogo entre saberes e pela emergência de outras epistemes e vozes que foram sendo ocultadas, silenciadas ou invisibilizadas no processo de constituição da sociedade moderna colonial. Numa tentativa de entender como foi construída ao longo dos séculos a sociedade moderno-colonial, analisaremos a crítica feita pelos estudos decoloniais a uma ciência moderna ocidental sem sujeito espacial, de "lugar nenhum", não localizado, atópico.

Grosfoguel (2008) analisa, por exemplo, o mito do conhecimento neutro e universal da ciência moderna ocidental ao afirmar que "na Filosofia e nas ciências ocidentais, aquele que fala está escondido, oculto e apagado da análise. A 'egopolítica do conhecimento' da filosofia ocidental sempre privilegiou o mito de um 'Ego' não situado. O lugar epistêmico étnico$\mathrm{racial} / \mathrm{sexual} / \mathrm{de}$ gênero e o sujeito enunciador encontram-se, sempre, desvinculados [leia-se descontextualizados]. Ao quebrar a ligação entre o sujeito da enunciação e o lugar epistêmico étnico-racial/sexual/de gênero, a filosofia e as ciências ocidentais conseguem gerar um mito sobre um conhecimento universal verdadeiro que encobre, isto é, que oculta não só aquele que 
fala como também o lugar epistêmico geopolítico e corpo-político das estruturas de poder/conhecimento colonial, a partir do sujeito que se pronuncia" (GROSFOGUEL, 2008, p. 22). A partir dessa perspectiva analisaremos a construção de uma espacialidade cultural neocolonial latino-americana.

\section{Geopolítica do conhecimento e colonialidade do saber e do poder}

A invenção da América no ano de 1492 permitiu a formação do sistema-mundo moderno, conforme definição de Immanuel Wallerstein (1984). Essa América inaugurou uma transformação econômica, política e cultural porque criou um imaginário geográfico mundial que perdura até os dias de hoje em nossa formação social. A partir desse momento muitos países europeus lançaram-se ao mar e o mundo começou a ser pensado por um centro, a Europa, sendo que todos os outros continentes irão se constituir enquanto sua periferia. Daí que se estabeleceu a relação entre as metrópoles (europeias) e as colônias (americanas, africanas e asiáticas). Desse acontecimento resultou que o mundo moderno passou a ser narrado e teorizado de dentro desse sistema colonial mundial, enquanto uma multiplicidade de outras narrativas e experiências históricas foram deliberadamente sendo deixadas de lado, ocultadas, invisibilizadas e negadas.

Todorov (1996, p. 6) considera, embora se utilizando do termo "descoberta da América", que "O século XVI veria perpetrar-se o maior genocídio da história da humanidade. Mas, não é unicamente por ser um encontro extremo, e exemplar, que a descoberta da América é essencial para nós, hoje. Além deste valor paradigmático, ela possui outro, de causalidade direta. A história do globo é, claro, feita de conquistas e derrotas, de colonizações e descobertas dos outros; mas, como tentarei mostrar, é a conquista da América que anuncia e funda nossa identidade presente. Apesar de toda data que permite separar duas épocas ser arbitrária, nenhuma é mais indicada para marcar o início da era moderna do que o ano de 1492, ano em que Colombo atravessa o Oceano Atlântico. Somos todos descendentes diretos de Colombo, é nele que começa nossa genealogia - se é que a palavra começo tem um sentido. Desde 1492 estamos, como disse Las Casas, 'neste tempo tão novo e a nenhum outro igual (...)'. A partir desta data, o mundo está fechado (apesar de o universo tornar-se infinito)". Ou seja, a partir dessa data o "mundo está fechado", pois passa a ser pensado e gerido por um centro, a Europa, que começa a articular o colonialismo como relação social de exploração e dominação dos outros continentes, sua periferia. 
Canclini (2003) afirma que o colonialismo costuma ser associado somente ao período colonial, aproximadamente do início do século XVI até o início do século XIX. Depois desse período o que se desenvolvia na América Latina era o início da modernidade e o processo de formação dos Estados nacionais, depois que diversos países obtiveram independência da Espanha ou de Portugal. De forma linear o colonialismo estruturou o passado latinoamericano e, sob esse ângulo, o "período colonial" é percebido como anterior à "modernidade", não como sua face oculta. É necessário, assim, ver que durante o período colonial havia modernidades coloniais, do mesmo modo que na modernidade erigiram-se colonialidades modernas.

Por isso, nossa experiência colonial latino-americana não acabou com o término do período colonial, ou com o fim do colonialismo como forma de exploração comercial. Essa herança do passado não foi superada em nossa imaginação, na maneira de nos relacionarmos com o Outro, muito menos na direção como construímos o conhecimento, produzimos "territórios", desenhamos nossas territorialidades, organizamos as instituições, vivemos em sociedade.

Se, como assegura Mignolo (2003), o fim do colonialismo na América Latina como relação de dominação econômica e política ocorreu na segunda metade do século XIX, isso não quer dizer que houve um encerramento da colonialidade do saber e do poder traduzida como relação social, cultural e de produção do conhecimento. Essa experiência colonial não é algo que desapareceu de nossa sociedade; muito pelo contrário, ela interfere diretamente em nossas ações e comportamentos, práticas, hábitos e nas visões de mundo que construímos. A colonialidade é uma marca impregnada em nossa formação latino-americana e que se expressa das mais variadas formas em nossas instituições como nas universidades, igrejas, partidos políticos, movimentos sociais, grupos e classes sociais, ONGs, dentre outras.

$\mathrm{Na}$ perspectiva decolonial de compreensão do mundo é impossível entender a modernidade sem pensar a colonialidade. A modernidade é parte da colonialidade e viceversa. O mundo moderno ou o sistema mundial é construído por essa tensão entre modernidade e colonialidade que, por esse motivo, devem ser vistas e analisadas como processos extremamente imbricados. Pensar a modernidade ocidental sem a sua contraface, a colonialidade, é invisibilizar outros sujeitos, outros territórios e territorialidades que foram ocultados por um longo processo de dominação e exploração colonial, o que se caracterizou como uma "Geografia das ausências" em diálogo a uma "Sociologia das ausências" de Boaventura de Sousa Santos (2004). 
As epistemologias do Sul desenvolvidas por Boaventura de Souza Santos (2004) permitem estabelecer um diálogo entre a "Sociologia das ausências" e a "Geografia das ausências" para vislumbrar uma "Geografia das emergências". Essa produção de ausências no pensamento geográfico tem sido visto de forma crítica pelo conhecimento espacial/territorial produzido pelas geógrafas e geógrafos latino-americanos que trabalham com os movimentos sociais de luta por corpo, terra e território.

Na tentativa de superar essa "Geografia das ausências", reconhecendo outras formas de vida, o corpo-terra-território emerge como categoria da prática e dispositivo de resistência dos povos indígenas e comunidades tradicionais contemporâneas que contestam e combatem a razão moderno-capitalista-colonial-patriarcal da sociedade em que vivemos e de ciências eurocêntricas. Desde as lutas indígenas, campesinas, quilombolas e feministas da América Latina são produzidas outras formas de conhecimento geográfico, geralmente negados, mas que atualmente disputam espaços de reconhecimento da diferença étnica e racial e de redistribuição econômica.

Por isso, uma forma de repensar a modernidade é "inseri-la" numa geopolítica do conhecimento que a pensa por meio da colonialidade do poder e do saber (QUIJANO, 2005). Esse deslocamento nos leva a ver que a modernidade tem o outro lado da moeda, a colonialidade, e que esta é o seu lado reverso, o lado que se quer ocultar, esconder, porque, silenciando-a, calam-se outras vozes, diversos sujeitos que carregam diferentes possibilidades de imaginar e fazer o mundo, enfim, ocultam-se (ao mesmo tempo em que se revelam) novas geografias. Por isso, a necessidade de pensar a dimensão espacial encaixada no sistema mundial moderno, pois essa perspectiva não é inscrita à concepção linear da moderna história ocidental:

\footnotetext{
A dimensão espacial do sistema permite a reflexão a partir de suas margens externas, onde a diferença colonial era e continua sendo exaurida. Até o meio do século 20 a diferença colonial respeitava a distinção clássica entre centros e periferias. Na segunda metade do século 20, a emergência do colonialismo global, gerenciado pelas corporações transnacionais, apagou a distinção que era válida para as formas iniciais de colonialismo e colonialidade do poder. No passado a diferença colonial situava-se lá fora, distante do centro. Hoje emerge em toda parte, nas periferias dos centros e nos centros das periferias (MIGNOLO, 2003, p. 9. [grifos nossos]).
}

É importante compreender os sujeitos e os processos de tensões, disputas e conflitos entre territorialidades na América Latina, inseridos, dentro dos limites geo-históricos do sistema colonial-moderno. A contextualização histórica e geográfica é fundamental para desvendar a geopolítica do sistema mundial colonial/moderno, suas fronteiras internas 
(conflitos entre cosmologias no interior de um Estado-nação), e externas (conflitos entre países), e situar o colonialismo como processo inerente à própria modernidade. Ou seja, a modernidade não é tão limpa assim como parece, ela carrega o trabalho, o suor, o sangue e a riqueza de povos ou comunidades tradicionais, de saberes suprimidos e da natureza expropriada e explorada pelo processo colonial denominado colonialismo.

Nesse conflito entre cosmologias nas fronteiras internas da modernidade-colonial, é fundamental reconhecermos o fenômeno do "colonialismo interno" analisado por González Casanova (2006), para compreender a dimensão histórica e geográfica dos contatos interétnicos entre povos indígenas e as frentes extrativistas, mineradoras, colonizadoras e pioneiras no movimento de formação dos Estados nacionais como, por exemplo, no Brasil, a partir do início do século XX, e que resultaram nas tensões e conflitos territoriais. A noção de colonialismo interno está associada à estrutura colonial como um fenômeno interno da estrutura social das novas nações.

Essa estrutura interna colonial, o colonialismo interno, apresenta enormes variações na hierarquia das classes sociais, nas diferenças das relações entre cidade-campo, além das múltiplas etnias exploradas e também de "diferenças de civilização". González Casanova (2002, p. 99) afirma que o "colonialismo interno corresponde a uma estrutura de relações sociais de domínio e exploração entre grupos culturais heterogêneos, diferentes". Trata-se, assim, de um instrumento analítico que pode ser a base para a emergência de movimentos sociais de luta, resistência e autonomia no interior dos Estados territoriais no contexto brasileiro-latino-americano.

Se a colonização europeia expressa à acumulação de capital na história do sistema mundial colonial-moderno devemos, pela colonialidade do saber e do poder, como defende Quijano (2005), criar um novo lócus de enunciação e de reflexão para pensarmos a história espacial do capitalismo sobre ângulos mais diversos, localizados nas margens, e que se constituem pela incorporação e diálogo com outros saberes - aqueles que foram subalternizados pelo processo hegemônico da formação das ciências eurocêntricas - por uma nova geopolítica do conhecimento.

Na perspectiva decolonial, devemos realizar uma "arqueologia do saber e do poder" por aquilo que Foucault (1999) chamou de "insurreição de saberes subjugados" ao descrever a transformação epistemológica em curso pelos conteúdos históricos que foram soterrados ou deixados de lado pela produção e institucionalização do conhecimento moderno-ocidental. Trata-se da "insurreição dos saberes sujeitados" ao "fazer que intervenham saberes locais, descontínuos, desqualificados, não legitimados, contra a instância teórica unitária que 
pretendera filtrá-los, hierarquizá-los, ordená-los" e tudo "em nome de um conhecimento verdadeiro, em nome dos direitos de uma ciência que seria possuída por alguns" (p. 13). Como afirma:

(...) por 'saberes sujeitados', eu entendo igualmente toda uma série de saberes que estavam desqualificados como saberes não conceituais, como saberes insuficientemente elaborados: saberes ingênuos, saberes hierarquicamente inferiores, saberes abaixo do nível do conhecimento ou da cientificidade requeridos. E foi pelo reaparecimento desses saberes de baixo, desses saberes não qualificados, desses saberes desqualificados mesmo, foi pelo reaparecimento desses saberes: o do psiquiatrizado, o do doente, o do enfermeiro, o do médico, mas paralelo e marginal em comparação com o saber médico, o saber do delinquente etc. - esse saber que denominarei, se quiserem, o 'saber das pessoas' (e que não é de modo algum um saber comum, um bom senso, mas, ao contrário, um saber particular, um saber local, regional, um saber diferencial, incapaz de unanimidade e que deve sua força apenas à contundência que opõe a todos aqueles locais das pessoas, desses saberes desqualificados, que foi feita a crítica" (FOUCAULT, 1999, p. 12).

Para além do conhecimento considerado científico, devemos "resgatar" genealogicamente o "saber das pessoas" que é "um saber particular, um saber local, regional, um saber diferencial". O filósofo irá chamar de "genealogia" o método para "resgatar" e trazer a cena os "saberes sujeitados" pelo "acoplamento dos conhecimentos eruditos e das memórias locais, acoplamento que permite a constituição de um saber histórico das lutas e a utilização desse saber nas táticas atuais" (FOUCAULT, 1999, p. 13).

Com isso a genealogia irá travar uma luta epistêmica contra os próprios efeitos de poder dos discursos considerados científicos ao demonstrar quem esse discurso legitima, quem ele invisibiliza, quem o exerce e quem se "empodera" com ele. No fundo, traz à cena outros discursos considerados pelo projeto científico da modernidade ocidental como “desqualificados”. Isso, segundo Foucault (1999), irá proporcionar “uma inserção dos saberes [sujeitados] na hierarquia do poder próprio da ciência, uma espécie de empreendimento para dessujeitar os saberes históricos e torná-los livres", isto é, "capazes de oposição e de luta contra a coerção de um discurso teórico unitário, formal e científico" (p. 15).

O que se questiona então é: de quem é o direito de dizer que um conhecimento é ou não científico? Na América Latina esse tipo de conhecimento denominado científico foi produzido nos moldes eurocêntricos, ou seja, por formas de saber que não estavam localizadas dentro da configuração epistemológica greco-romana e cristã, tendo na razão e na escrita o alicerce para os métodos oriundos da Ciência. Entretanto, como afirma Mignolo (2003), as disciplinas das Ciências Sociais não podem permanecer como árbitro intelectual de projetos globais, desvinculadas das histórias locais. Mas, se o momento em que vivemos a 
globalização cria condições para a construção e reprodução de saberes eurocêntricos, baseados na razão e cada vez mais especializados na moderna tecnologia, como os saberes locais sujeitados podem ser inseridos no interior da academia?

É necessário que a Geografia, enquanto Ciência Social, resgate outras vozes e, por conseguinte, outros saberes "desqualificados" pelo método científico de perspectiva positivista, linear, "progressiva", e que possa incorporar ao seu discurso as histórias (ou experiências) locais nos conhecimentos produzidos. Na América Latina, e particularmente no Brasil contemporâneo, trazer para o interior da discussão os saberes tradicionais e locais dos povos indígenas, comunidades quilombolas, populações tradicionais, dentre outros sujeitos subalternizados na formação da sociedade moderno-colonial, suas histórias e geografias de múltiplas escalas e de várias fronteiras, permitirão uma descolonização dos poderes diante dos conflitos territoriais para a construção de práticas de luta e resistência. Partir da geografia que dá vida às relações desses sujeitos e nisso compreender os processos pode ser um caminho epistemológico que reconhece a "força do lugar", como assegurou Milton Santos (2004).

Podemos, com isso, reagir não apenas contra a formação de um imaginário geográficocolonial dominante, mas, também, contra a atualidade desse imaginário discurso-prática colonial na sociedade, nos discursos e representações sociais, no tocante à subalternização de conhecimentos, por exemplo, de grupos indígenas na América Latina. Essa reação configurase como uma alternativa para trazer à agenda de discussões outros sujeitos que foram ocultados pelo modelo eurocêntrico.

No movimento da modernidade, que atribui uma história linear da sociedade ligada ao progresso, as instituições de ensino são impregnadas, em parte, por visões eurocêntricas nas quais se desenvolveram as disciplinas das Ciências Sociais. Na América Latina muitos saberes foram anulados, destruídos e revelados em nome do progresso e do desenvolvimento de uma ciência eurocêntrica, modelo importado da Europa e transplantado no novo continente a serviço do colonialismo. Muitas histórias, vivências, memórias, tradições foram deliberadamente silenciadas, como a dos povos indígenas, quilombolas, sem-terra, periféricos, trabalhadores, dentre outros.

O geógrafo Porto-Gonçalves (2007, p. 218) considera que na América Latina muitas geografias foram ocultadas nesse processo. Outros lugares ficaram de fora ou à margem da modernidade, ou quando incorporados, as chamadas modernidades coloniais construíram uma desigual relação de troca e uma supressão das diferenças em favor do colonizador. Os "lugares coloniais" e seus respectivos sujeitos foram invisibilizados, o que provocou uma supressão de geografias. Para o autor, a colonialidade do poder e do saber ajuda-nos a 
recuperar a simultaneidade e a multiplicidade dos diferentes lugares na conformação de nosso mundo. Essa visão abre espaço para que múltiplas epistemes dialoguem. Mais do que hibridismos, devemos reconhecer nesse processo que pensamentos devem aprender a viver entre lógicas distintas, a se mover entre códigos diferentes, para que ressurjam várias epistemes e estabelecem um diálogo de saberes. É claro que não podemos esquecer que a modernidade ajudou, mesmo que na maioria das vezes pelo lado dos sujeitos hegemônicos, a revelar diferenças, a produzi-las e a torná-las parte de nossa formação latino-americana.

Segundo Quijano (2005), o processo civilizatório instaurado pela modernidade ocidental imprimiu uma violência de matrizes do colonialismo e da colonialidade do saber e do poder como forma binária de superioridade "natural", seja ela étnica e/ou racial, do europeu sobre outros povos. Segundo ele, para reconstruirmos nosso imaginário geográfico devemos considerar a colonialidade do poder e do saber. Mas, em que sentido a colonialidade do saber e do poder nos ajuda a pensar a atual reconfiguração da economia e do imaginário mundial?

Castro-Gómez (2005) considera que, no processo de "re-invenção do Outro" pela modernidade, a proposição de Anibal Quijano da colonialidade do poder e do saber permite ver que as formas de controle social não tinham como objetivo somente dominar pela força outros povos e destruí-los ou dizimá-los. Esse processo objetivava, também, transfigurar suas almas com o propósito de transformar intensamente suas formas tradicionais de conhecer o mundo e a si mesmo. Isso fazia o colonizado ver e crer com o próprio universo cultural, político e econômico do colonizador.

A colonialidade do poder e do saber é um projeto de dominação que não utiliza apenas estratégias de violência e/ou de força, de repressão contra o colonizado. Mais do que isso, implica uma passagem ou mudança radical dos costumes, das práticas e das maneiras de pensar o mundo. É uma forma de controle da sociedade e de autocontrole das emoções (ELIAS, 1994), com estratégias que variam desde a coerção pura e "simplesmente" física até as repressões religiosas, afetivas e morais.

Para Mignolo (2003, p. 41), Quijano identifica a colonialidade do poder e do saber com o capitalismo e sua consolidação na Europa dos séculos XV a XVIII, que se constitui por meio de algumas características:

A classificação e reclassificação da população do planeta - o conceito de "cultura" torna-se crucial para essa tarefa de classificar e reclassificar; 
Uma estrutura funcional institucional para articular e administrar tais classificações (aparato de Estado, universidades, igreja etc.);

$>$ A definição de espaços adequados para esses objetivos e

Uma perspectiva epistemológica para articular o sentido e o perfil da nova matriz de poder e a partir da qual canalizam a nova produção de conhecimento.

Em suma, a colonialidade do poder e do saber é um processo pelo qual o planeta inteiro é articulado pela Europa para a produção do conhecimento ao estabelecer um modelo classificatório que parte e tem como centro as instituições, os valores e os objetivos de um projeto em torno da modernidade ocidental. Entretanto, um "espaço eurocêntrico" definido pelos hegemônicos e consequentemente pelo "centro" do mundo - euro + cêntrico - também foi reproduzido no interior da própria Europa. Como sabemos esse continente não é homogêneo muito menos difunde somente valores e saberes europeus ocidentais - ou "razões eurocêntricas" -, tendo em vista a diversidade de posições e de culturas que influenciaram na formação (e influenciam, ainda, hoje) dessa porção do planeta e as que resistem ao processo de "eurocentrização".

\section{Descolonizar territórios e territorialidades}

Não podemos esquecer que as próprias raízes do pensamento decolonial são europeias - ou "híbridas" com este pensamento - como demonstram, por exemplo, Fanon (2005) já citado aqui, e Saïd (2007), que considera o Orientalismo como a "invenção do Oriente pelo Ocidente" ao afirmar que "o Orientalismo é - e não apenas representa - uma dimensão considerável da moderna cultura político-intelectual e, como tal, tem menos a ver com o Oriente do que com o 'nosso' mundo" (p. 60). Além da separação entre duas partes desiguais, o Oriente e o Ocidente, esse tipo de pensamento envolve "“interesses' que, por meios como a descoberta erudita, a reconstrução filológica, a análise psicológica, a descrição paisagística e sociológica, o Orientalismo não só cria, mas igualmente mantém" (p. 40) uma realidade supostamente diferente ou alternativa como forma de "controlá-la" ou até mesmo "incorporála" ao mundo moderno-ocidental.

É fundamental para pensarmos essa questão a análise feita por Foucault (2010) sobre a posição protagonista do Ocidente em relação ao mundo (sem desconsiderar as influências do mundo árabe, Oriente Médio ou mundo persa), quando ele afirma que essa "espécie de região 
geográfica" desenvolveu "nosso destino de homem moderno" ao impor "suas maneiras de ver, pensar, dizer e fazer ao mundo inteiro". Assim:

\begin{abstract}
Quero dizer que muitas coisas, muitas práticas sociais, práticas políticas, econômicas nasceram e se desenvolveram, com enorme força, em uma espécie de região geográfica que se situa entre o Vístula e Gilbraltar, entre as costas do norte da Escócia e a ponta da Itália. Não quero dizer absolutamente que o mundo árabe, por exemplo, não teve influência sobre tudo isso... ou o Oriente Médio, ou o mundo persa... Resta, não menos que nosso destino de homem moderno desenvolveu-se nessa região e durante uma certa época que se situa entre o começo da Idade Média e os séculos XVIII ou XIX. A partir do século XIX, é preciso dizer que os esquemas de pensamento, as formas políticas, os mecanismos econômicos fundamentais que eram aqueles do Ocidente tornaram-se universais, pela violência da colonização, enfim, a maior parte do tempo, tornaram-se, de fato, universais. $E$ isso que entendo como Ocidente, essa espécie de pequena porção do mundo cujo destino estranho e violento foi de impor suas maneiras de ver, pensar, dizer e fazer ao mundo inteiro. É verdade que o mundo se revoltou contra esse Ocidente, que se separou dele, que tenta agora... que coube a ele perder sua posição preeminente, mas isso não impede que os instrumentos que foram empregados no mundo inteiro para reproduzir o Ocidente e sacudir seu jugo, esses instrumentos, é o Ocidente que os forjou quase todos (FOUCAULT, 2010, p. 157. [grifos nossos]).
\end{abstract}

Trata-se do que Castro-Gómez (2005, p. 83) denominou, baseado na intelectual indiana Gayatri Spivak, "projeto da modernidade como o exercício de uma violência epistêmica", que excluiu a possibilidade de representação do seu mundo e da sua autorrepresentação pelo anulamento e/ou apagamento de outras práticas de sociabilidade, de um conjunto de bens simbólicos, de representação e subjetivação das experiências e da destruição dos lugares que possibilitavam a vivência de formas concretas, pois permitiam o registro das memórias e experiências individuais e coletivas.

Essa negação e supressão da diversidade de saberes são chamadas por Sousa Santos (2004) de "epistemicídio", a forma de traduzir e expressar como a riqueza de ideias e/ou de epistemes do mundo foi sendo aniquilada por uma razão universalizante e que se quer totalitária da racionalidade capitalista e moderna. A racionalidade se manifesta pela exclusividade epistemológica, pautada numa cosmovisão arraigada no modelo europeu, manifestado nas concepções de ciência que concebem a nossa forma de construir teorias e conceitos e na maneira como fazemos nossa leitura do mundo, de nós mesmos e principalmente do Outro.

A herança colonial, com as suas diferenças e resíduos irredutíveis, continua viva e influencia diretamente na produção do conhecimento no Brasil, sobre grupos subalternos, conforme o caso das representações e visões construídas historicamente de forma negativa e/ou pejorativa sobre os povos indígenas, comunidades quilombolas e populações tradicionais. A colonialidade do saber e do poder atua sobre esses sujeitos de várias maneiras, 
seja ocultando-os da história, invisibilizando-os do espaço, estereotipando-os nos lugares e inferiorizando-os na relação com o moderno.

É importante, nesse sentido, discutirmos as estratégias de luta pela terra e de subalternização política, epistêmica e ética que esses sujeitos realizam, e construir um esforço de descolonização do pensamento, da história e geografia oficiais cristalizadas no Brasil, para deslocar o terreno de enunciação à perspectiva subalterna/colonial. Urge descolonizar e remapear territórios e territorialidades e trazer para a agenda de discussões os sujeitos "ocultos" das narrativas e espaços eurocêntricos por outra geopolítica do conhecimento.

No magma de significações históricas, construiu-se um imaginário social e geográfico sobre a região América Latina no mundo, e de seus lugares, por um conjunto de representações, narrativas, imagens e ideologias sobre os povos que tradicionalmente ocupam essa região como os povos indígenas. Este conjunto de imagens, representações e narrativas, com uma forte imaginação geográfica colonial, ainda hoje está presente nos discursos do Estado, do capital, da mídia, dos fazendeiros, nas escolas, em parte nas universidades e em uma parcela majoritária da população. Em sua maioria os fazendeiros agronegócio brasileiro justificam a acumulação e a concentração da propriedade privada da terra como uma "territorialização" capitalista moderna e inferiorizam o Outro, o indígena, via de regra, pelo apelo ao discurso competente do imaginário colonial.

Marilena Chauí (2007) afirma que o discurso competente (como o próprio discurso “científico") é um discurso instituído por uma linguagem institucionalmente permitida e autorizada, não acessível para qualquer um, no interior de uma formação social específica: "O discurso competente é o discurso instituído. É aquele no qual a linguagem sofre uma restrição que poderia ser assim resumida: não é qualquer um que pode dizer a qualquer outro qualquer coisa em qualquer lugar e em qualquer circunstância. O discurso competente confunde-se, pois, com a linguagem institucionalmente permitida e autorizada, isto é, com um discurso no qual os interlocutores já foram previamente reconhecidos como tendo o direito de falar e ouvir, no qual os lugares e as circunstâncias já foram predeterminados para que seja permitido falar e ouvir e, enfim, no qual o conteúdo e a forma já foram autorizados segundos os cânones da esfera de sua própria competência” (CHAUÍ, 2007, p. 19).

Esse discurso autorizado faz o uso de um imaginário geográfico colonial para a construção de um estereótipo que direciona a uma estigmatização ou invisibilidade desses povos. Nessas representações existe uma forma de "produção da verdade", por um discurso competente da modernidade que impõe a subalternização dos povos oriundos de várias fronteiras étnicas que antecedem aquelas dos Estados-nacionais. 
Dussel (2005) considera que para a superação da modernidade será necessário negar o mito construído em torno da modernidade reconhecendo que, do outro lado, do lado colonial dessa fronteira, temos a vítima desse processo. Com isso nega-se a inocência da modernidade trazendo a alteridade sofrida nesse processo pelo Outro, negado antes como "vítima culpada", e que por essa matriz de pensamento pode revelar a face oculta da modernidade: o "mundo periférico colonial, o índio sacrificado, o negro escravizado, a mulher oprimida, a criança e a cultura popular, alienadas (as vítimas da Modernidade) como vítimas de um ato irracional (como contradição do ideal racional da própria Modernidade)" (p. 29). Somente quando se nega a inocência do mito civilizatório da violência moderna é que se pode reconhecer a injustiça da prática sacrificadora adotada fora da Europa (e até mesmo na Europa) como na América Latina, África e Ásia.

Sob essa ótica a modernidade inclui a alteridade como uma perspectiva criadora de novas formas de sociabilidade entre, como definiu Todorov (1996), o nós, que corresponde aos europeus, e os outros, que somos os povos do mundo periférico brasileiro-latinoamericano. Este processo de reconhecer a alteridade como parte integrante da modernidade não é novo, pois como afirmamos anteriormente, as próprias raízes do pensamento póscolonial são europeias. Tanto na Sociologia, como na Antropologia, na Arte e especialmente na Literatura, temos vários exemplos daqueles que buscaram demonstrar a diversidade e/ou heterogeneidade cultural de nosso continente. Neste sentido é premente adotar outra perspectiva na análise cultural da América Latina, em que se destaca a teoria literária, para cartografar as identidades culturais que foram ocultadas.

De saída, podemos dizer que o próprio nome América Latina é colonial e traz no seu bojo uma série de complexidades e conflitos inerentes ao colonialismo que, como analisamos, ainda afetam nosso imaginário geográfico e nossas concepções/cosmovisões de mundo. A ideia de América Latina foi utilizada como forma de confrontar a expansão imperialista dos Estados Unidos. Surgiu para distinguir as expressões Latino e Anglo-Saxão e como uma maneira de representar e ao mesmo tempo diferenciar os sujeitos de cada região. Essa oposição geopolítica entre Latinos e Anglo-Saxões é inerente à formação do termo América Latina e nasce, segundo Morse (1988, p. 15), pelo uso "napoleônico" do termo por uma visão eurocêntrica, pois é "parte de um discurso 'geoideológico' para suposta unidade linguística, cultural e 'racial' dos povos latinos, em contraposição aos germânicos, anglo-saxões e eslavos".

Quental (2010), baseado nas reflexões realizadas por Mignolo, afirma que antes de 1492, a América Latina não estava presente em nenhum mapa ou representação do globo. Até 
esse momento a cosmologia cristã compartimentava o mundo em apenas três continentes: Ásia, África e Europa. Isso não quer dizer que outras civilizações, não ocidentais, partilhassem desse mesmo imaginário regional de mundo que foi representado no mapa cristão do $\mathrm{T}$ em $\mathrm{O}$. Desta divisão tripartida de mundo, surgirá à base de elaboração dos mapas-múndi dos séculos XVI e XVII. Assim:

O termo América, como sabemos, é uma homenagem a Américo Vespúcio, comerciante e navegador italiano que observou que as terras encontradas por Cristóvão Colombo anos antes, em verdade, não se tratavam das Índias (Ocidentais), mas de um Novo Mundo. (...) Para que estivesse acomodado ao imaginário de mundo do período, o termo recebe uma flexão de gênero gramatical para o feminino, combinando, então, com as designações Ásia e África (...). Com o advento da conquista e a incorporação de um quarto continente ao quadro de mundo cristão, as designações 'Índias Ocidentais' e 'Novo Mundo', duas outras formas como também foram batizadas as novas possessões coloniais de Espanha e Portugal, são inseridas no imaginário de mundo europeu e coexistem com a designação de América (...). Até 1492, o centro do mundo cristão era localizado em Jerusalém e, Europa, portanto, encontrava-se ao Ocidente, a Oeste deste centro. Com o surgimento das Índias Ocidentais no imaginário de mundo cristão, América passa a configurar o extremo ocidente deste cenário, deslocando Europa - e o Ocidente, portanto - para o centro do quadro (QUENTAL, 2010, p. 55, 56 e 57).

Reis (2009), nessa direção, levanta a seguinte questão: de que espaço falamos quando nos referimos à América Latina? A América Latina carrega uma combinação de componentes de colonialidade que complexificam esse espaço. Internamente cada contexto geográfico carrega uma imensa carga histórica, inclusive dos nossos colonizadores. Desde o aspecto colonial que advém da Península Ibérica, Portugal e Espanha, os países colonizadores demonstram, por exemplo, que o termo Ibero-América vem do colonizador grego quando chegou à Península Ibérica, já a designação Espano-América atribuída pela Espanha é oriunda do Império Romano quando colonizou a Península Ibérica.

$\mathrm{Na}$ América Latina, em relação a outros contextos da própria periferia mundial, o pensamento decolonial está situado dentro de uma determina perspectiva de mundo. Por isso, não podemos esquecer que esse contexto geo-histórico colonial é marcado pela exploração econômica violenta, escravagista e patriarcal, em nome da constituição do sistema mundo moderno. Isso nos leva, então, a refletir no contexto latino-americano como esse pensamento decolonial permite construir conhecimentos e práticas verdadeiramente descolonizadoras por meio das lutas por corpo, terra e território de povos indígenas e comunidades tradicionais.

Frente à modernidade monocultural é necessário pensar outras formas de conhecimento e construir brechas como alternativas epistêmicas. Uma possibilidade é incorporar o conhecimento popular, indígena, campesino, quilombola, feminista, desde a 
perspectiva das epistemologias do Sul (SANTOS, 2004), decolonial, para elaborar e produzir um conhecimento alternativo e que sirva como ferramenta de resistência para os grupos em luta. Estabelecer um diálogo de saberes, uma ecologia de saberes, numa perspectiva construtivista, pode fazer avançar o pensamento geográfico, espacial e territorial, no sentido que permita reconhecer outras formas de relação entre humanos e não humanos, como propõe Bruno Latour (2004).

É necessário superar os essencialismos e avançar no sentido de romper com a relação entre sujeito-objeto como propõe o perspectivismo e o multinaturalismo (VIVEIROS DE CASTRO, 2015). Essa ecologia de saberes sugere rever esse jogo dualista e propõe uma possibilidade multi-dialógica, rizomática, no sentido de compreender os territórios de existência por meio da dimensão ontológica (ESCOBAR, 2018), ou talvez, pluriontológica, facilitando o trânsito entre culturas, esse ir e vir de territorialidades que configura novas territorialidades, transterritorialidades (MONDARDO, 2018), para uma "ética ecológica" (ARGOTA CAICEDO, 2018).

\section{Considerações finais}

Embora a designação América Latina apresente impropriedade, é importante considerar que desde esse espaço decolonial povos indígenas e comunidades tradicionais configuram de algum modo o seu próprio mundo, o seu próprio universo. Se por um lado a América Latina é marcada fortemente pela herança escravista, patriarcal e colonial, por outro, esse espaço apresenta a potência da biodiversidade e a força de resistência da etnodiversidade.

O elemento central que o pensamento decolonial nos coloca é a ideia de que esse conhecimento é sempre localizado. Esse pensamento está situado em uma determina perspectiva de mundo que, no caso da América Latina, como analisamos, existe uma carga histórica de violência da economia extrativista espoliadora.

Mas, então, o que é esse movimento de descolonização dos espaços e horizontes latinoamericanos? Antes e para além da soberania dos Estados-nações, a América Latina foi/é construída pelas histórias vividas e quanto maior e mais diversos forem os números de narrativas, melhor poderemos verificar a diversidade desse espaço. A "colonialidade do saber e do poder" (QUIJANO, 2005) faz com que a fronteira tenha uma cosmovisão única e linear (do progresso) de seu espaço, baseada na perspectiva eurocêntrica. Essa cosmovisão exclui e marginaliza povos indígenas e comunidades tradicionais que vivem em espaços periféricos e/ou estão subalternizados. 
Na América Latina o “colonialismo interno” (GONZÁLEZ CASANOVA, 2006) construiu e atualizou lógicas territoriais de espoliação de recursos (da terra, água, floresta, entre outros), e da exploração do trabalho indígena. Na relação com a Europa, as fronteiras latino-americanas, bem como outros espaços periféricos, foram sendo hierarquizados pela colonialidade do saber e do poder por meio de epistemologias e ontologias modernas. Assim foram sendo consideradas como inferiores - com vistas à dominação - por espaços europeus. Como resultado desse processo, o continente latino-americano tem priorizado muitas vezes os grupos etnocêntricos e de culturas hegemônicas, nem sempre ligadas organicamente a esse espaço, o que atualiza práticas territoriais neocolonialistas, capitalistas e patriarcais e reforça o racismo epistémico.

O debate sobre a descolonização de territórios na América Latina diz respeito aos esforços ontológicos (das lutas) e epistemológicos (teóricos) dos povos originários/indígenas, comunidades quilombolas, populações tradicionais, grupos subalternizados/colonizados em busca de reconhecimento de seus direitos como terras, territórios, saúde e educação. Esses sujeitos lutam para mostrar que existe uma megadiversidade/demodiversidade de espaços de vida (mundos plurais), de produção de conhecimentos que foram historicamente invisibilizados em favor de uma ciência europeia ocidental que se construiu como a única capaz de produzir saberes modernos e que prega, ainda, hoje, a neutralidade e a universalidade.

A colonialidade do saber e do poder ignorou os saberes populares, indígenas, campesinos, quilombolas, que são produzidos no território em uma perspectiva comunitária. Esses grupos sociais produzem um conhecimento geográfico próprio a partir da estreita relação com seu território como espaço de práticas, de vida e lutas. A cosmovisão é exercida por meio da territorialidade ancestral. É possível afirmar que os territórios de povos indígenas e comunidades tradicionais produzem conhecimentos populares geradores de práticas espaciais alternativas e descolonizadas como caminho para a resistência anticapitalista. Assim, é importante reconhecer o pluriverso das lutas territoriais e emancipatórias, num mundo onde caibam outros mundosterritórios construídos por meio da potencialidade das pluriterritorialidades. Devir-minoria, devir-povo, devir-território.

\section{Referências}

ARGOTA CAICEDO, G. Ética ecológica: una reconfiguración cultural del sentido de la naturaleza. Utopía y Praxis Latinoamericana, 23(83), 2018, pp. 1-16.

CANCLINI, N. G. Culturas híbridas: estratégias para entrar e sair da modernidade. 4 ed. São Paulo: EdUSP, 2003. 
CASTRO-GÓMES, S. Ciências sociais, violência epistêmica e o problema da "invenção do outro". In: LANDER, E. (Org.). A colonialidade do saber: eurocentrismo e ciências sociais: perspectivas latino-americanas. Buenos Aires: CLACSO, 2005, pp. 80-87.

CHAUÍ, M. Cultura e democracia: o discurso competente e outras falas. 12 ed. São Paulo: Cortez, 2007.

DARDOT, P.; LAVAL, C. Commun: essai sur la révolution au XXIe siècle. Paris: La Découverte, 2014.

DUSSEL, E. Europa, modernidade e eurocentrismo. In: LANDER, E. (Org.). A colonialidade do saber: eurocentrismo e ciências sociais Perspectivas latino-americanas. Buenos Aires: CLACSO, 2005, pp. 8-23.

ELIAS, N. O processo civilizador. Rio de Janeiro: Jorge Zahar Editor, 1994.

ESCOBAR, A. Otro posible es posible: caminando hacia las transiciones desde Abya Ayala/Afro/Latino-América. Bogotá: Ediciones Desde Abajo, 2018.

FANON, F. Os condenados da terra. Juiz de Fora: Ed. UFJF, 2005.

FOUCAULT, M. Ditos e Escritos VI: Repensar a política. Rio de Janeiro: Florense Universitária, 2010.

FOUCAULT, M. Em defesa da sociedade: curso do Collège de France (1975-1976). São Paulo: Martins Fontes, 1999.

GALEANO, E. De Las venas abiertas de América Latina a Memoria del fuego. Montevideo: Universidad de la República, 1987.

GONZÁLEZ CASANOVA, P. Colonialismo interno (una redefinición). In: BORON, A. AMADEO, J. GONZÁLEZ, S. (Orgs.). La teoría marxista hoy. CLACSO, Buenos Aires, 2006, p. 431-458.

GROSFOGUEL, R. La descolonización de la economía política y los estudios postcoloniales: transmodernidad, pensamiento fronterizo y colonialidad global. Tabula Rasa. Bogotá Colômbia, n. 4, Janeiro-junho de 2006, p. 17-48.

GROSFOGUEL, R. Hacia un pluri-versalismo transmoderno decolonial. Tabula Rasa. Bogotá - Colombia, n. 9, julho-dezembro de 2008, p. 199-215.

LATOUR, B. Políticas da natureza: como fazer ciência na democracia. Bauru, SP: Edusc, 2004.

LEMINSKI, P. Distraídos venceremos. São Paulo: Brasiliense, 1987.

KRENAK, A. Ideias para adiar o fim do mundo. São Paulo: Companhia das Letras, 2019. 
MIGNOLO, W. Histórias locais/projetos globais: colonialidade, saberes subalternos e pensamento liminar. Belo Horizonte: UFMG, 2003.

MONDARDO, M. Territórios de trânsito: dos conflitos entre Guarani e Kaiowá, paraguaios e "gaúchos" à produção de multi/transterritorialidades na fronteira. Rio de Janeiro:

Consequência, 2018.

MORSE, M. R. O espelho de próspero: cultura e ideias nas Américas. São Paulo: Companhia das Letras, 1988.

PORTO-GONÇALVEZ, C. W. A invenção de novas geografias: a natureza e o homem em novos paradigmas. In: Território, territórios: ensaios sobre o ordenamento territorial. Rio de Janeiro: Lamparina, 2007.

QUENTAL, P. de A. Entre o fato e o artefato: notas sobre a invenção do conceito de América Latina. Dissertação de Mestrado. Programa de Pós Graduação em Geografia, Universidade Federal Fluminense. Niterói, 2010.

QUIJANO, A. Colonialidade do poder, eurocentrismo e América Latina. In: LANDER, E. (Org.). A colonialidade do saber: eurocentrismo e ciências sociais. Perspectivas latinoamericanas. Buenos Aires: CLACSO, 2005, pp. 107-130.

REIS, L. Conversas ao Sul: ensaios sobre literatura e cultura latino-americana. Niterói: EdUFF, 2009.

SAÏD, E. W. Orientalismo: o Oriente como invenção do Ocidente. São Paulo: Companhia das Letras, 2007.

SANTOS, M. A natureza do espaço: técnica e tempo, razão e emoção. 4. ed. São Paulo: EDUSP, 2004.

SANTOS, B. de S. Para uma Sociologia das Ausências e uma Sociologia das Emergências. In: SANTOS, B. de S. (Org.). Conhecimento prudente para uma nova vida decente: um discurso sobre as ciências revisitado. São Paulo: Cortez, 2004.

SVAMPA, M. Neo-extractivism in latin america: socio-environmental conflicts, the territorial turn, and new political narratives. New York: Cambridge University Press, 2019.

TODOROV, T. A conquista da América: a questão do outro. São Paulo: Martins Fontes, 1996.

WALLERSTEIN, I. The Politics of the World-Economy: The States, the Movements and the Civilizations. Cambridge: Cambridge University Press, 1984.

VIVEIROS DE CASTRO, E. Metafisicas canibais. São Paulo: CosacNaify, 2015. 